\title{
Complete resection of intracardiac leiomyomatosis through an abdominal approach under peripheral cardiopulmonary bypass
}

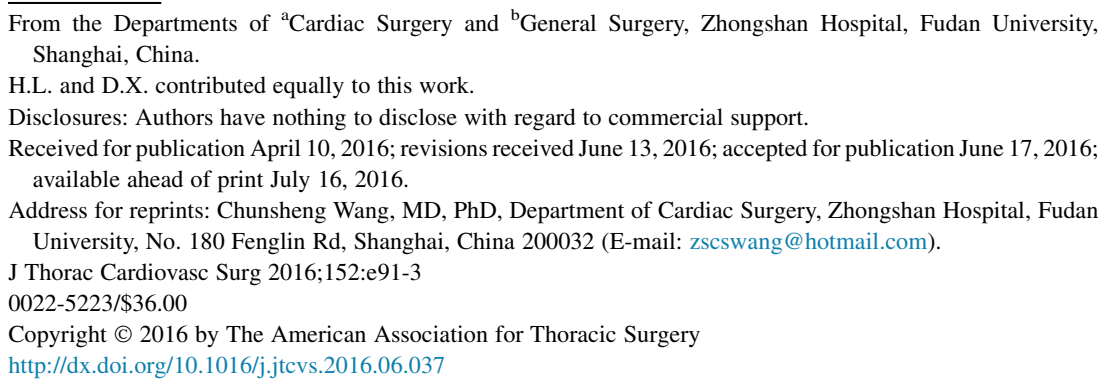

From the Departments of ${ }^{\mathrm{a}}$ Cardiac Surgery and ${ }^{\mathrm{b}}$ General Surgery, Zhongshan Hospital, Fudan University, Shanghai, China.

H.L. and D.X. contributed equally to this work.

Disclosures: Authors have nothing to disclose with regard to commercial support.

Received for publication April 10, 2016; revisions received June 13, 2016; accepted for publication June 17, 2016; available ahead of print July 16, 2016.

Address for reprints: Chunsheng Wang, MD, PhD, Department of Cardiac Surgery, Zhongshan Hospital, Fudan University, No. 180 Fenglin Rd, Shanghai, China 200032 (E-mail: zscswang@ hotmail.com).

J Thorac Cardiovasc Surg 2016;152:e91-3

$0022-5223 / \$ 36.00$

Copyright (C 2016 by The American Association for Thoracic Surgery

http://dx.doi.org/10.1016/j.jtcvs.2016.06.037

Hua Li, MD, PhD, ${ }^{a}$ Demin Xu, MD, ${ }^{a}$ Weiqi Lu, MD, ${ }^{b}$ and Chunsheng Wang, MD, PhD, ${ }^{a}$ Shanghai, China

\section{PTCS \\ VIDEO}

Video clip is available online.

Intracardiac leiomyomatosis (ICL) is a rare benign disease. An ICL is defined as an intravenous leiomyomatosis extending to the heart through the inferior vena cava (IVC). Several surgical strategies have already been established according to the morphology of the ICL. ${ }^{1,2}$ This case study introduces a strategy of single-stage resection through a laparotomy under peripheral cardiopulmonary bypass (CPB).

A 62-year-old woman without previous medical illness was seen with anorexia. Computed tomography (Figure 1, $A$ ) and echocardiography (Figure $1, B$ ) revealed a mass in the right ovarian vein extending through the IVC into the right ventricle. The surgical team decided to pull out the intracardiac part through cavotomy with the aid of peripheral CPB.

On median laparotomy, the IVC between the level of the renal veins and the level of several centimeters below the ovarian vein was exposed and suspended with umbilical tapes. After heparinization, the extracorporeal circuit was set up with the left femoral artery cannulation with an $18 \mathrm{~F}$ cannula. Venous drainage was achieved by cannulations of the left femoral vein with a $24 \mathrm{~F}$ cannula and the right internal jugular vein with a $16 \mathrm{~F}$ cannula placed through a percutaneous puncture. No chest incision was involved, and the heart continued beating.

After the initiation of CPB under normothermia, a 5-cm longitudinal cavotomy was made at the level of right ovarian vein inlet. The bleeding was controlled by umbilical tapes around the cavotomy and aspirated by 2 intracardiac suction devices. The upper part of the tumor was gently

\section{CLINICAL SUMMARY}

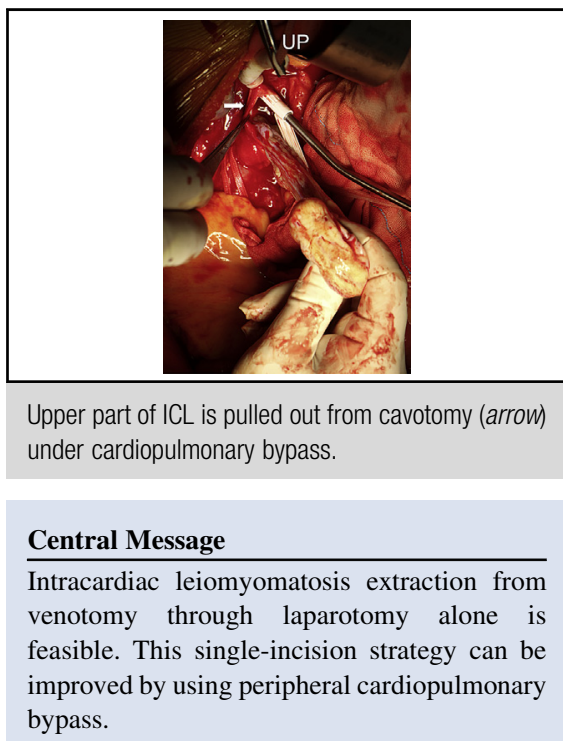

See Editorial Commentary page e93. pulled out under surveillance of transesophageal echocardiography (Figure 1, C). The right ovarian vein and the tumor were excised together with a small ellipse of vena cava to which the tumor adhered (Figure 1,D). After suture of the cavotomy, CPB was tapered and protamine was administrated. The total hysterectomy and bilateral salpingooophorectomy procedure was performed by gynecologist afterward (see details in Video 1).

CPB time was 20 minutes. Operative time was 3.5 hours. The blood loss was merely $100 \mathrm{ml}$ with no blood transfusion. Histological analyses confirmed the diagnosis of ICL. The patient recovered uneventfully and was discharged on the tenth postoperative day. The patient is doing well without recurrence (Figure 1,E) 3 months after surgery.

\section{DISCUSSION}

Resections of the intracardiac and intravenous tumors through atriotomy and venotomy in a one-stage or twostage manner are the common strategies for surgical treatment of $\mathrm{ICL}^{1,2}$; however, patients have to undergo double incisions (ie, thoracotomy and laparotomy). Unlike other intra-IVC tumors, such as the friable renal tumor, ICL is characteristically of high tensile strength. We once hung weights equal to $1 \mathrm{~kg}$ on an ICL that had been resected through a sternolaparotomy approach, and the tumor tissue 

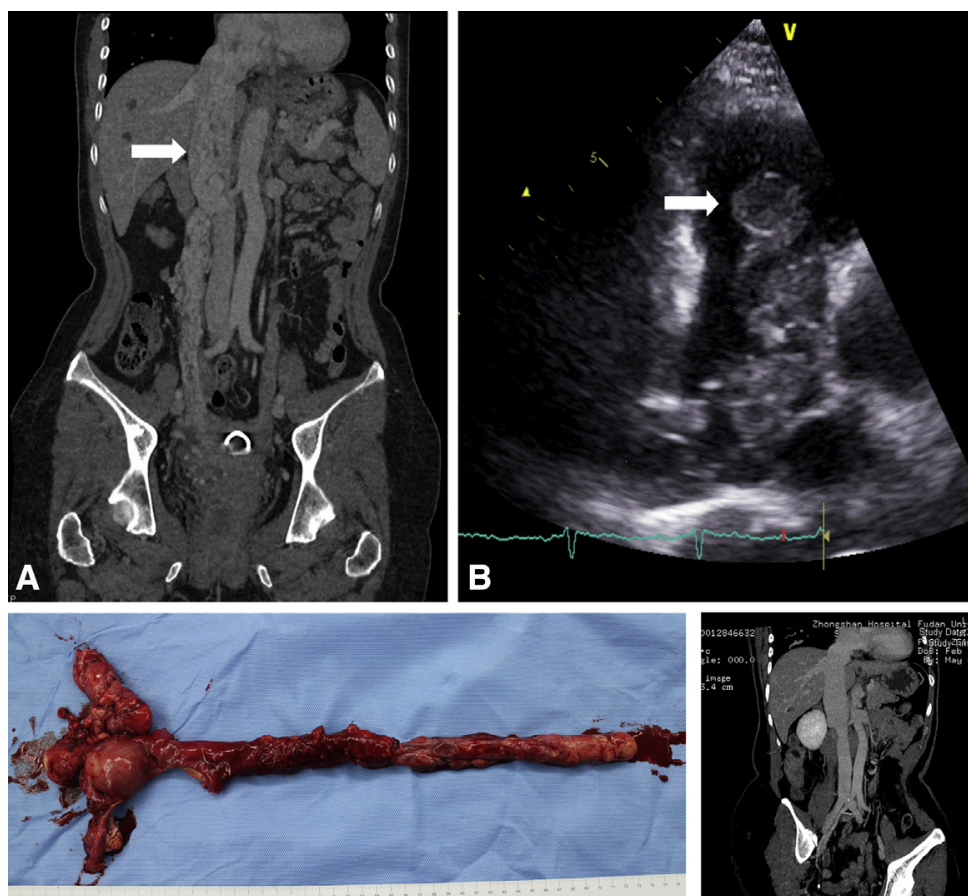

D
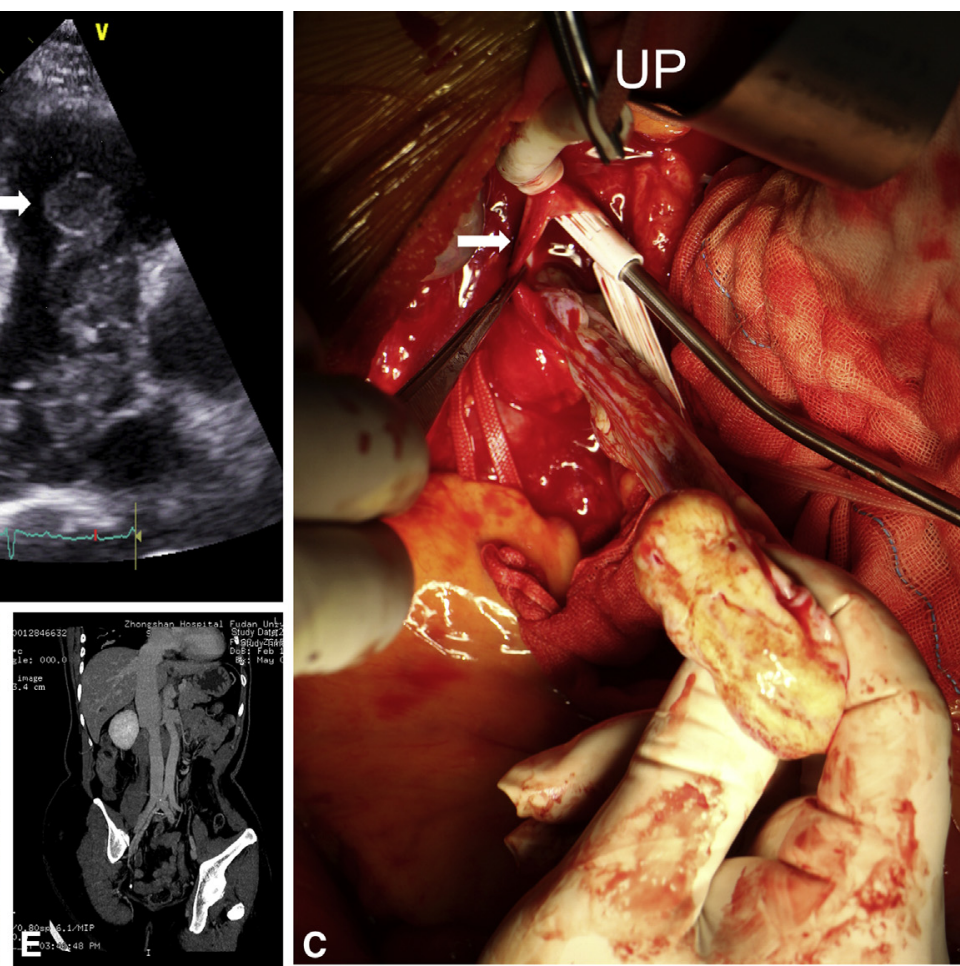

FIGURE 1. A, Computed tomography showing a tumor embolism (arrow) originating from the uterus and extending into the inferior vena cava through the right ovarian vein. B, Transthoracic echocardiogram showing a wormlike mass (arrow) extending into the right cardiac chambers. C, The upper part of tumor is pulled out from the cavotomy (arrow) under cardiopulmonary bypass. D, The resected tissues are a 34-cm long tumor embolism, the right ovarian vein, the uterus, and bilateral adnexa. E, Computed tomography showing no recurrence 3 months after the operation.

was not torn apart by such pulling force (Video 1). The intracardiac part of the tumor can be technically extracted from infradiaphragmatic venotomy if the diameter of it is smaller than the orifice of IVC inlet. Furthermore, the small-diameter tumor means that the tumor lies freely inside the heart chambers and is not likely to adhere to endocardium or the tricuspid valve. For these, extraction of tumor can be achieved by venotomy through a laparotomy alone, through which the hysterectomy and bilateral salpingo-oophorectomy can be concomitantly performed.

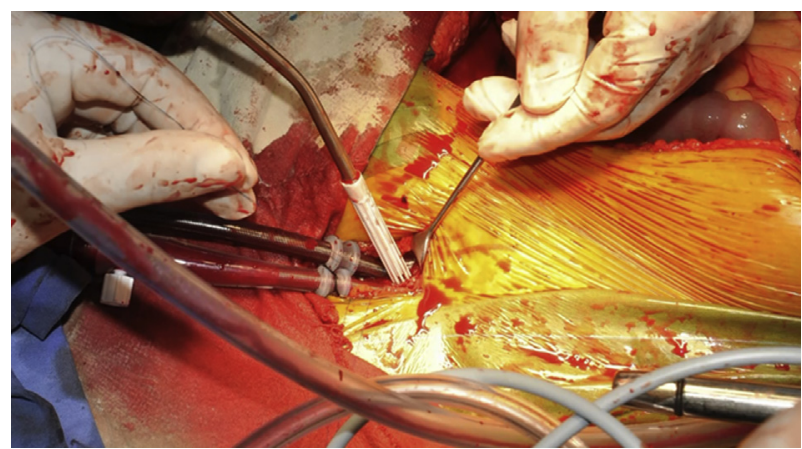

VIDEO 1. Video clip shows the morphologic details of the tumor, the details of the surgical procedure, and a tensile strength test of the tumor tissue.
Only 10 cases $^{1,3-5}$ out of more than 200 cases of $\mathrm{ICL}^{2}$ reported in the literature have had complete resection undertaken through a laparotomy alone. This suggests that the practice of this single-incision strategy is not commonly considered for ICL. It is also notable that no CPB was ever applied in the 10 cases in which the abdominal approach was undertaken. ${ }^{1,3-5}$ As a matter of fact, this procedure often runs the risk of massive blood loss for tumor thrombectomy without the protection of CPB, especially in the case of a dilated tumor larger than the size of IVC, multiple strands of tumor, or adhesions to the IVC which requiring extensive venotomy. Tumor thrombectomy under CPB is reliable without risk of hemodynamic instability and blood loss from venotomy. The avoidance of CPB might be the reason that the application of this single-incision approach is not common. The case reported here demonstrates that CPB by peripheral cannulation without sternotomy plays a facilitative role in this very scenario.

On the basis of our experience, adequate surgical field suction by 2 roller-pump suction devices and proper control of major veins can create a relatively bloodless surgical field. Deep hypothermia and circulatory arrest, which require a sternotomy, thus can be avoided. Protamine should be administrated before the pelvic resections to minimize bleeding.

In conclusion, ICL extraction through an infradiaphragmatic venotomy can be improved by peripheral $\mathrm{CPB}$. This strategy is expected to expand the indication of 
single-stage resection through a laparotomy alone for the ICL without intracardiac dilation.

\section{References}

1. Gan HL, Zhang JQ, Zhou QW, Kong QY, Zhao S, Bo P. Surgical treatment of intracardiac leiomyomatosis. J Thorac Cardiovasc Surg. 2011;142:823-8.

2. Li B, Chen X, Chu YD, Li RY, Li WD, Ni YM. Intracardiac leiomyomatosis: a comprehensive analysis of 194 cases. Interact Cardiovasc Thorac Surg. 2013; $17: 132-8$.
3. Matsuo K, Fleischman F, Ghattas CS, Gabrielyan AS, Ballard CA, Roman LD et al. Successful extraction of cardiac-extending intravenous leiomyomatosis through gonadal vein. Fertil Steril. 2012;98:1341-5.e1.

4. Subramaniam B, Pawlowski J, Gross BA, Kim YB, LoGerfo FW. TEEguided one-stage excision of intravenous leiomyomatosis with cardiac extension through an abdominal approach. J Cardiothorac Vasc Anesth. 2006;20:94-5.

5. Harris LM, Karakousis CP. Intravenous leiomyomatosis with cardiac extension: tumor thrombectomy through an abdominal approach. J Vasc Surg. 2000;31: 1046-51.

\title{
EDITORIAL COMMENTARY
}

\section{Case reporter's notebook: The who, what, when, where, how, and why of extraction of a benign intracaval tumor}

\author{
Verdi J. DiSesa, MD, MBA
}

From the Lewis Katz School of Medicine at Temple University, Philadelphia, Pa.

Disclosures: Author has nothing to disclose with regard to commercial support.

Received for publication June 20, 2016; accepted for publication June 21, 2016; available ahead of print July 14, 2016.

Address for reprints: Verdi J. DiSesa, MD, MBA, Lewis Katz School of Medicine at Temple University,

3500 North Broad St, MERB 11, Philadelphia, PA 19140 (E-mail: verdi.disesa@tuhs.temple.edu).

J Thorac Cardiovasc Surg 2016;152:e93-4

$0022-5223 / \$ 36.00$

Copyright (C) 2016 by The American Association for Thoracic Surgery

http://dx.doi.org/10.1016/j.jtcvs.2016.06.030

\section{WHO}

A patient who successfully underwent removal of a benign tumor extending into the inferior vena cava (IVC).

\section{WHAT}

Complete resection of intracardiac leiomatosis via laparotomy and an incision in the IVC under cardiopulmonary bypass with a beating heart and without deep hypothermia and circulatory arrest.

\section{WHEN}

Resection of intracaval tumor at the same time and through the same incision as planned hysterectomy and bilateral salpingo-oophorectomy.

\section{WHERE}

The entire operation was performed through a laparotomy incision without thoracotomy and with peripheral cardiopulmonary bypass. Arterial cannulation was in the femoral artery with venous cannulation of the femoral and jugular veins. The IVC was isolated and controlled between the renal veins and several centimeters below the ovarian vein that was the entry point of the tumor into the vena cava.

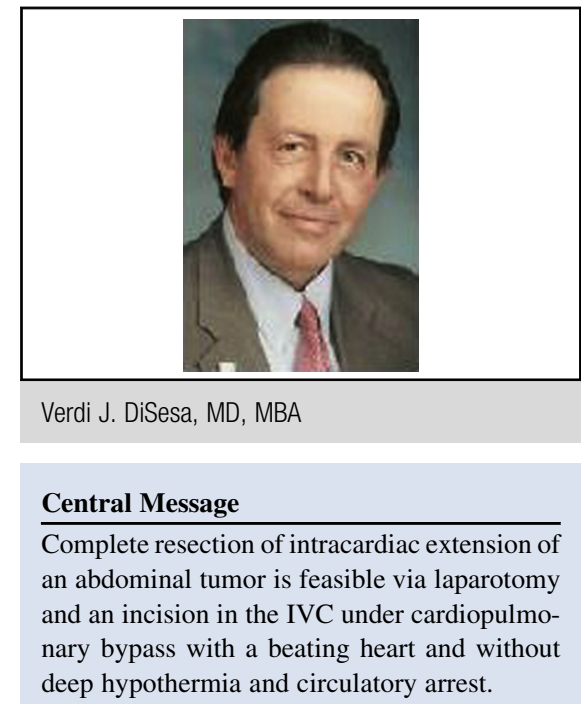

See Article page e91.

\section{HOW}

After laparotomy and isolation of the IVC, peripheral cardiopulmonary bypass was initiated. The heart remained beating throughout the procedure. The distal vena cava was controlled by constriction of the distal umbilical tape encircling the IVC near the ovarian vein. Until it was removed, the tumor thrombus controlled bleeding from the proximal cava and pump suckers were used to maintain a reasonably dry field. After removal of the tumor, the proximal caval tape was tightened to secure retrograde bleeding. 